\title{
In Whose Best Interest? A Canadian Case Study of the Impact of Child Welfare Policies in Cases of Domestic Violence
}

\author{
Ramona Alaggia, Angelique Jenney, Josephine Mazzuca, and \\ Melissa Redmond
}

Version Published Version/Final PDF

Citation Alaggia, R., Jenney, A., Mazzuca, J., \& Redmond, M. (2007). In Whose (published version) Best Interest? A Canadian Case Study of the Impact of Child Welfare Policies in Cases of Domestic Violence. Brief Treatment and Crisis Intervention, 7(4), 275-290. doi:10.1093/brief-treatment/mhm018

Copyright / License CC BY-NC-ND

How to cite TSpace items

\begin{abstract}
Always cite the published version, so the author(s) will receive recognition through services that track citation counts, e.g. Scopus. If you need to cite the page number of the author manuscript from TSpace because you cannot access the published version, then cite the TSpace version in addition to the published version using the permanent URI (handle) found on the record page.
\end{abstract}

This article was made openly accessible by $U$ of $T$ Faculty.

Please tell us how this access benefits you. Your story matters. 


\title{
In Whose Best Interest? A Canadian Case Study of the Impact of Child Welfare Policies in Cases of Domestic Violence
}

\author{
Ramona Alaggia, MSW, PhD \\ Angelique Jenney, MSW \\ Josephine Mazzuca, PhD \\ Melissa Redmond, MSW
}

\begin{abstract}
North American child protection systems have been experiencing an era of sweeping child welfare reform over the last decade. Despite the breadth of these changes, legislative and policy impacts are rarely evaluated to ascertain whether changes are resulting in the outcomes they were designed to achieve. Using a participatory research framework, 70 participants from relevant service sectors and service recipients from a large urban centre in Canada, were interviewed about legislation in cases of children exposed to domestic violence. While most stakeholders noted the "spirit of the Act" to be well-meaning and based on a credible body of child research, there were serious concerns cited with the implementation and impact of policies that resulted from this piece of child welfare legislation. Reluctance of abused women to disclose or seek services for their families, isolation between helping professionals from different sectors, increased demand for services, increased surveillance of mothers, and decreased accountability of perpetrators were predominant themes identified. These data strongly suggest that response models be tested as pilot studies, rigorously evaluated and fully implemented only when there are assurances that appropriate and adequate services are available to meet the complex needs of the communities they are designed to serve.
\end{abstract}

KEY WORDS: domestic violence, child abuse, child maltreatment, qualitative research.

Over the past decade, North American child protection services have experienced an era of sweeping child welfare reforms. The predomi-

From the Faculty of Social Work, University of Toronto (Alaggia, Redmond) and Child Development Institute, Toronto (Jenney, Mazzuca).

Contact author: Ramona Alaggia, Associate Professor, Faculty of Social Work, University of Toronto, 246 Bloor Street West, Toronto, Ontario M5S 1A1, Canada.

E-mail: ramona.alaggia@utoronto.ca.

doi:10.1093/brief-treatment/mhm018 nant changes reflected in these reforms include the implementation of risk assessment models and family preservation initiatives, the strengthening of "the best interest of the child" principles, an increased emphasis on child neglect, the redesigning of permanency planning, and the implementation of differential response models. Despite the breadth of these reforms, legislative and policy impacts have not been sufficiently evaluated to determine if the reforms are achieving their desired outcomes.

(c) The Author 2007. Published by Oxford University Press. All rights reserved. For permissions, please e-mail: journals.permissions@oxfordjournals.org. 
Legislative amendments to the Ontario Child and Family Services Act were implemented in 2000. These amendments resulted in more emphasis being placed on investigating children exposed to domestic violence (DV). The recognition of exposure to DV as a form of child maltreatment represented a shift in child protection services. As a result of most provinces across Canada recognizing exposure to DV as a form of child abuse, it has become clear that exposure of children to DV occurs with alarming frequency and these children are increasingly coming to the attention of child welfare authorities. Child welfare agencies across Canada have experienced a dramatic rise in reports of emotional abuse, a large proportion of which are children exposed to DV (Trocmé et al., 2005).

In Ontario, where the present study was conducted, the reported rate of exposure to DV increased by $319 \%$ between 2000 and 2005 (Fallon et al., 2005). Cases involving DV are also the most frequently substantiated form of child maltreatment (Trocmé et al., 2005). Clearly, in light of these numbers, such changes have significantly affected how professionals in related sectors work with children and families and given rise to growing concerns about child welfare policies and practices that respond to exposed children. Yet, the impact of these policies on professionals and their clients had not been investigated in this jurisdiction.

This article reports on a qualitative study that sought to understand the implications of child welfare reporting policies on professional practice, on mothers' willingness to disclose intimate partner violence knowing that child welfare involvement may be an outcome, and on experiences of mothers with the child welfare system and other related service sectors.

DV is a pervasive and concerning social phenomenon in Canada. Statistics Canada (2005) reports that $7 \%(653,000)$ of all Canadian women have experienced some form of spousal abuse in a current relationship in the preceding
5 years. When women were asked about incidences of abuse they have experienced in any previous relationship, $21 \%$ of Canadian women reported incidences of violence (Statistics Canada, 2005). It is widely recognized that women often face a host of barriers that may limit their choices about how to respond to violence in their relationships. Women's rights advocates point to a myriad of reasons to explain why many women are unable to leave abusive relationships; they acknowledge that leaving an abusive relationship is a difficult process that may take several attempts (Hilton, 1992). Among the factors that may inhibit women's choices about dealing with violence are economic barriers, emotional dependence, cultural and religious prohibitions regarding separation and divorce, problematic custody and access orders, and the dangers of increased lethality involved in leaving (Alaggia, 2001; Lee, 2000; McDonald, 1999; Pagelow, 1992; Sev'er, 2002; Shaffer \& Bala, 2004; Shirwadkar, 2004). Of note, women who leave relationships in which they are being battered are more likely to be murdered than women who stay (Davis \& Srinivason, 1995; Mahoney, 1991).

For immigrant and refugee women, the notion of disclosing abuse or leaving the abusive partner is further complicated by the fear of disapproval by her cultural communities, negative consequences of such actions on her immigration status, especially if sponsored by her husband, economic and language barriers, and fear of dealing with unfamiliar legal systems (Alaggia \& Maiter, 2006; Lee, 2000; McDonald, 1999; Pratt, 1995; Shirwadkar, 2004).

Women involved in abusive relationships may not be the only ones impacted by the violence. According to the Canadian 2004 General Social Survey, in one third of self-reported cases of spousal violence, victims also reported that their children saw or heard the violence. In the most recent Transition Home Survey, between April 
1, 2003, and March 31, 2004, more than 95,000 women and children were admitted to 473 shelters across Canada, the majority of whom were escaping abusive relationships (Taylor-Butts, 2005). Because reporting domestic abuse is difficult for many women and many parents mistakenly believe they are shielding their children from exposure to violence, it is safe to assume that these numbers are underestimates.

There is a growing body of evidence documenting the serious and persistent negative effects of childhood exposure to woman abuse. Exposure to DV may impact a child's social, psychological, and behavioral functioning; some children require lengthy and expensive treatment as a result (Edleson, 1999; Wolfe, Crooks, Lee, McIntyre-Smith, \& Jaffe, 2003). When compared to children who have not witnessed woman abuse, exposed children show greater internalizing behavior problems (depression, anxiety, social withdrawal), greater externalizing behavior problems (hyperactivity, aggression), more aggressive social problem-solving strategies, lower social competence, lower self-esteem, lower school performance and academic achievement, poorer information intake capacities, lower levels of curiosity and distortion of neutral information, poorer performance on intelligence tests, greater posttraumatic stress disorder symptomology, more attributions of self-blame and guilt for the violence, less secure attachments with caregivers, and more difficulties in affect regulation and physical symptoms such as headaches and stomachaches (Edleson, 1999; Jaffe, Wilson, \& Wolfe, 1988; Wolfe et al., 2003). Some research also suggests that children exposed to DV are more likely to perpetrate violence against others. This particular finding supports social learning theory, which suggests that exposure to DV in childhood may condition a new generation of abusers and victims, thus continuing the cycle of violence (Cummings, 1998; McGee, 2000).
Several methodological limitations hamper investigation in this area. Most studies neither distinguish among co-occurring forms of abuse nor separate these effects from those of children who are only exposed to DV. This research often relies on shelter samples in which the effects of poverty are significant and may account for poorer child outcomes. Other studies rely on mothers' reports of their children's behaviors and issues (self-selection and self-reports) and do not use collateral sources of information. Children's resilience to violence is an area that is just now beginning to be better understood, including identifying protective factors and coping mechanisms, which can influence the impact and outcome of DV exposure. Yet, these significant findings are not fully integrated in policy and practice. Finally, few studies employ an experimental design utilizing control groups.

In an effort to serve the best interests of children, child welfare systems have developed policies and practices based on the documented detrimental effects of witnessing violence, without addressing these methodological shortcomings. A clear illustration of this conflict is the inclusion of childhood exposure to DV as a form of child maltreatment and the simultaneous "failure to protect" provisions employed by child welfare workers when DV does not stop. Admittedly, these are not easily resolved issues. On the one hand, children's emotional, social, and physical well-being need to be considered and protected, and on the other hand, for a number of women leaving an abusive relationship may not be possible for some time. When abused mothers do not leave abusive relationships, they can be held responsible for exposing their children to continued violence and may have their children removed for child endangerment under this legislation. However, when put to the legal test in New York City by a group of mothers who were victims of DV and had their children 
taken into protective custody, a federal judge found that constitutional rights and that such a policy was unconstitutional (Nicholson $v$. Williams, 2002).

Numerous Canadian and American researchers have raised questions about the reach of child welfare laws, suggesting that perhaps these have gone too far and women are being inadvertently revictimized by the child welfare system (Edleson, 2004; Jaffe, Crooks, \& Wolfe, 2003; Magen, 1999; Magen, Conroy, \& Del Tufo, 2000). Some of this research suggests that the unintended consequences of these policies may be driving serious social problems "underground." For example, Jaffe et al. (2003) highlight that current legal and policy responses to children exposed to DV may inadvertently create conditions where woman abuse victims are hesitant to disclose the violence. Accordingly, they recommend evaluating the intended and unintended consequences of Canadian legal and policy responses on children exposed to woman abuse.

\section{Method}

\section{Objectives}

The aim of this study was to examine and assess the implications of child welfare reporting legislation for women who are victims of DV, their children, and the service professionals who help them and their families. The study was conducted in a large urban setting in Ontario, Canada. The overarching research questions were developed after a review of the literature and an environmental scan with child welfare agencies and related service sectors (area of service provision including health care providers, legal professionals, and child welfare workers). The environmental scan was completed through a consultation with groups of helping professionals and academics
(Roundtable on Child Welfare Practices in Woman Abuse Cases, University of Toronto, July 2004). The following key research questions were developed: (a) What is the impact of child welfare legislation that defines children's exposure to DV as a form of child maltreatment on disclosure of woman abuse?; (b) What is the impact of child welfare policy on abused mothers accessing services for themselves and their children?; and (c) How does this legislation impact on the practices of social service providers in the Violence Against Women (VAW) sector, health care services, police, and the child welfare system?

The research questions were pursued within a participatory action research framework as described by Maguire (1997) and recommended by family violence researchers (Edleson, 1998; Gondolf, Yllo, \& Campbell, 1997; Renzetti, 1997; Riger, 1999). In order to reach out and identify major stakeholder groups, including abused women and the range of service providers, various data collection methods were utilized: (a) Key informant interviews with service providers (including police, shelter workers, VAW service providers, legal professionals, health care workers) and previous clients (mothers who had been investigated by child welfare authorities due to DV issues) to highlight salient issues in the field, assist in the development of interview guides, and identify other relevant stakeholders; (b) focus groups with mothers previously in abusive relationships who had child welfare contact, child welfare workers, and VAW service providers; and 3) gathering, compiling, and analyzing existing statistics, as collateral data, from social service agencies such as child welfare sources, health care settings, and VAW services where available. Data collection began in March 2005 and ended in November 2005.

A Research Advisory Committee was formed early in the project to ensure that the research process was guided by those affected by and 
working with the problems of DV and its impact on mothers and children. Quarterly meetings were held with the lead researchers during the course of the research. Survivors of DV on the Committee chose to participate through e-mail correspondence and telephone interviews for confidentiality reasons. Interview guides were developed by the researchers, and input was sought from committee members and survivors of DV to ensure that the areas addressed were relevant to all stakeholders involved. The study received institutional approval by the University of Toronto, Health Sciences I Ethics Review Committee, and two local Children's Aid Society ethics review boards. As with any research study involving people, especially those from vulnerable groups, measures to ensure confidentiality were stringently followed and written informed consent was sought from everyone participating in the research.

Key informant interviews and focus groups were audiotaped with the permission of participants. All interview tapes were subjected to intensive content analysis, which involved listening to the tapes to develop and identify emerging themes. A subsample of interviews (75\%) was analyzed using a qualitative data analysis software package, $\mathrm{N}^{*} \mathrm{Vivo}$, for lineby-line microanalysis to further refine theme development. Some interviews were deemed to be less relevant to the focus of the study because child welfare involvement occurred for issues other than DV; three key informants declined to be audiotaped and audio problems were experienced on another three.

The trustworthiness and authenticity of the data were established through maintaining detailed researcher notes, audiotapes, and transcriptions of the interviews, memos, and an audit trail. Analysis of data occurred with multiple coders to maximize consistency and breadth of themes and to reduce bias. Three researchers and two research assistants con- ducted independent analyses of the transcripts, which resulted in satisfactory agreement on themes and subthemes. In other words, each researcher independently identified themes that emerged from the data. As well, the thematic findings were reviewed on an ongoing basis by the Research Advisory Committee as a form of member checking.

Sampling for key informants was purposive with the intention of capturing the perspectives of various sectors of service delivery. The key informants included program administrators/ managers, frontline child welfare workers, social workers, child advocates, women's advocates, police, health care providers, legal professionals, and survivors of woman abuse. In total, 30 key informants were interviewed and 6 focus groups were conducted. Table 1 outlines the various participant groups and settings involved in this study.

Sampling for recipients of services was purposive and occurred through key informants who invited women for participation. Flyers were also posted in agencies. Researchers were given names of potential participants from service providers only with the consent of service recipients. Two focus groups were run with women who were survivors of DV. Women affected by violence who participated were given a small honorarium of $\$ 25$ to compensate for their time. Transportation, a meal over the dinner hour, and child care were also provided.

Exclusion criteria included ensuring that the woman was out of the abusive relationship to ensure her safety. Child welfare participants were workers and clients sampled from Jewish, Catholic, Aboriginal, mainstream child welfare services and ethno-specific agencies. Frontline workers and managers were interviewed, and women survivors of abuse represented young to middle-aged women, women from all socio-economic strata, Canadian born and immigrant women, as well as women from different racial and/or ethnic backgrounds. 
TABLE 1. Study Respondents

Key informant interviews

Eight child welfare informants (three administrators

and five frontline workers)

Eight VAW service providers

Two survivors of woman abuse

Four legal professionals

Four police officers

Four health care providers

Total: 30 individual key informant interviews
Focus groups

Three groups of child welfare workers

(total 18 individuals)

One VAW service provider (total six individuals)

Two groups of survivors of woman abuse

(total 16 individuals)

\section{Results}

Enduring themes emerged consistently from the key informant interviews and focus groups with service providers and service recipients. The themes were verified with the Research Advisory Committee as a means of member checking and are described as follows. Quotes are supplied for confirmability of findings.

\section{Themes}

Policy Impact on Professional Practice. The first predominant theme was the impact of the legislation on internal policies and practices of all the service sectors sampled. For example, shortly after the child welfare amendments in 2000, the police force in the jurisdiction of the study area implemented an internal policy to report to child welfare authorities all domestic dispute calls they responded to where they found evidence of children residing in the home. One police informant explained:

They will generally contact Children's Aid right from the house as well and they will advise the victim the purpose of that is to assist them as well. Those things are generally done right from the scene.... The call is made a good ninety-nine percent of the time.
Police key informants explained that child welfare agencies are best equipped to investigate and evaluate whether children are being emotionally harmed so they leave it to them to determine dispositions and take appropriate action.

Service providers in the VAW sector cited serious implications in having to report their clients to child welfare agencies. They explained that universal reporting practices potentially take control and choices away from women. Ultimately, women are held accountable for the abuse they experience from their partners and this diminishes or ignores perpetrator accountability. Although the majority of VAW workers agreed with, "the spirit of the Act," they recounted several unintended consequences of the duty to report. The primary consequence is on the relationship between workers and clients. This possible breach of trust may make women more reluctant to use shelters and other services. VAW service workers voiced concerns that often the mothers' safety is not considered as directly linked to that of their children and that this "disconnect" puts the family at risk. Finally, VAW workers highlighted their observations around victim blaming:

Ideally it could be that children were not taken away but both children and mom got the support, rather then her being punished 
which really that is how it is presented, 'you messed up and for whatever reason you weren't able to [leave]'. I think there is an underlying message of blame the woman for being in the situation that she is.

Respondents from the health care sector explained that child welfare legislation has created "confusion and anxiety for physicians." One health care key informant summarized:

There [are] two types of anxiety. One is, 'Am I doing the right thing?' 'Am I supposed to call on this?' 'What constitutes grounds for calling?' If you read the Act, it's not completely clear and so there is some ambiguity and that makes it hard for physicians. The other is, 'How will this impact on my relationship with this patient?' ' ... because disclosure is voluntary and we know there are lots of barriers which prevent women from disclosure already and if the need to report to child welfare may act as another barrier? 'Will this, in fact, prevent a woman from asking for assistance?'

Another identified concern is that of time restrictions for physicians and their reluctance to address the issue of DV with their patients. One key informant from the health care sector observed: "It is the reason why physicians don't ask about violence because if they get a yes answer it is going to throw a wrench into the rest of their day and they are going to have to deal with it and often it is better not to ask the question."

Finally, interpretation of the legislation regarding the reporting of exposed children differs, and as a result practices vary. For example, several key informants pointed out that differing interpretations of the legislation led to inconsistent referrals. One shelter worker explained, "We still have some schisms, for example the mandatory reporting. Some shelters are reading the Act differently."
Policy Impact on Disclosure and Reporting

of DV. A wide range of experiences were described by the mothers interviewed. Some mothers described their involvement with child welfare as brief but supportive and being limited to "checking in" after a referral had been made, ensuring that the perpetrator was out of the home, and referrals to community resources. As one participant describes:

I found it, actually, very helpful. The man I spoke to was kind. He was concerned. He asked how I was, was there anything they could do? Did you have plans and I told him I had a plan to come here [child therapy centre]. And he said, 'If there is anything else, you call us'. So it wasn't a threatening thing. It was a good thing.

Others reported a level of intrusion that was intimidating and blaming. One mother explained:

And it's like, I feel like, I am always battling. I talked with the worker yesterday and I said to her, I think, three times, 'We're not going to talk about me. We're going to talk about him and the children. We are not going to talk about me'. And, it takes so much to be able to do that and to get them to understand I am not the one who needs to be told.

This dynamic between workers and clients was echoed by some professionals. A women's service worker described her experience:

It starts up being woman abuse and the kid has witnessed it, then it ends up being does she have a job, does she have supports, how's her parenting? .... and if that woman has a criminal record, if she has been in the mental health system, disability, she is a Black woman, Aboriginal woman, young woman, the system will hold her and scrutinize her right because of class, race, and gender. 
Some women had previous involvement with child welfare, and although those issues may have been resolved earlier, they believed that any previous contact influenced the current investigation in a negative way. They felt misunderstood and wanted the opportunity to explain their situations more fully. Other women explained that although they feared and even resisted the involvement of child welfare authorities, it was that very involvement that really opened their eyes to the negative environment their children were living in and helped them make the decision to leave. In general, though, women voiced concerns that they felt they were being investigated when they were not the perpetrators of violence.

Overall, the precise impact of the legislation on women's disclosures is difficult to assess. Mothers' perceptions of what may happen appear to be a predominant factor in driving fear and apprehension of triggering a child welfare investigation. As one police key informant described:

The perception, I think, with a lot of women is that if they report something child welfare will be called and my child or children will be taken away. I think that perception is out there. Does that legislation have a direct effect on women not coming forward? I am sure it does. To what degree, it's really tough to know.

This view is further verified by observations made by a shelter worker immediately after the legislation was amended:

We had been working with women individually and in groups and we had to say that if things are going really badly at home right now we have to report to CAS. They all left the service, they felt so betrayed and even the women who were not directly affected were so angry at us.
Sectoral Isolation. Service providers consistently described feeling isolated from other sectors. Numerous reasons were cited, such as conflicting mandates of service provision, differing codes of professional conduct, power imbalances among systems, and competition for scarce resources.

There are numerous quotes from service providers and recipients to support observations of cross-sectoral isolation: "I am not convinced that we are all working in as integrated way as we could or should. That is, child welfare, authorities, police, perhaps the shelters ..." (Child Welfare Worker); "Right now we are not working as teams." (Health Care Provider); "It was my lawyer who I really, really trusted who also discouraged me, 'Don't get CAS involved. They will take your children away, etc."' (Survivor).

A lack of understanding of cross-sector mandates and inadequate communication appear to explain a large part of this isolation. For example, power imbalances between sectors were reported with some sectors being perceived as having more legislative powers. One VAW worker observed:

[The] other thing that happens, and this is a big problem, that once the referral is made, once the report is made, we don't know what happens. It is a black box. We don't know if child welfare investigated. Did they take action? Is the home safer? Is there a plan? We have no idea.

Professional colleges and associations influence how professionals from various sectors handle issues of consent and confidentiality. For example, health care providers and legal service professionals adhere to a different code of confidentiality than social workers. For physicians, consent issues figured prominently in their interviews, given that confidentiality is central to the physician-patient relationship. Pressure to report to child welfare without 
the patient's expressed consent put physicians in a dilemma. One physician explained the questions and dilemmas that "duty to report" raises for them: "Are they doing the right thing? How will this impact on the patientphysician relationship? Will this act as another barrier to disclosing woman abuse?" In contrast, social workers were very clear about their professional obligations to report child abuse, putting the best interest of the child ahead of other considerations, despite the impact on their relationship with parents.

Perpetrator Accountability. Except for the legal system, no other service sector professionals felt they had much opportunity, access, or competence to intervene with the abusive partner. First, most sector informants explained that they do not have the mandate to intervene with the offending partner. From the first point of referral, the case is opened in the mother's name: CAS is a scary system for women. Even the file is in the mother's name. I think we need to be focusing on the one causing the harm in the family. Why aren't they going after the abuser and using their power to keep him out of the home? Instead we are sending mothers to parenting groups (VAW service worker).

If the abusive partner is uncooperative, professionals cited that they cannot interview him. Often, the perpetrator is impossible to locate. For instance, several key informants mentioned that defense lawyers usually instruct their clients not to talk to child welfare authorities. A child welfare key informant described this dilemma:

I think it would be good if we could also make the perpetrator more accountable for what he has done in the sense that a lot of the times when they are charged with assaulting and they are given a certain order or conditions. We, a lot of times, don't know where that perpetrator is in terms of following up with that person. It's always because we don't know that person's whereabouts, we're following up with mom, following up with the children, but Dad's off the hook.

This is further verified by abused women as one survivor explained: "Why is this all up to me? How come? I refuse to believe the solution to this problem is the court system. Who's going to help my kids and who's going to sit down and tell this man that it is his responsibility to get therapy and to reconnect with these kids or to leave them alone?"

Second, most service providers feel they do not have the training to deal with the abusive partner. Another child welfare worker stated:

We're probably not very skilled as we should be in working with the fathers and it's pretty hard in a system to hold men accountable for their abusive behaviors if you never meet with them and never talk to them.

While the importance of accountability with the perpetrator is acknowledged, service providers believed that there are no mechanisms to ensure accountability:

No matter how you cut it, the abuser gets off most of the time. He is not held accountable and not made responsible, and the onus is still on the woman in keeping her kids safe. (VAW key informant)

\section{Marginalization Due to Race, Class, Sexual Orientation, Ability, and Immigration Status. These data clearly indi-} cate that women who are marginalized due to race, sexual orientation, immigration status, class, and ability have greater barriers in disclosing and accessing services for themselves and their children. These women include women of color, lesbian mothers, women with disabilities, mothers of children with disabilities, immigrant and refugee women, women without immigrant status, women of various 
cultural and religious backgrounds, financially disadvantaged women, and women with mental health issues or addictions. Fear of harsher treatment and discrimination based on skin color (for both their partners and themselves), lack of services for lesbian mothers and their children (gay positive environments), fear of deportation for recent immigrants or women sponsored by their partners, language obstacles, physically inaccessible services, and fear of losing school placements for children with disabilities were among the additional barriers identified as issues for woman survivors from marginalized communities.

Racial discrimination and prejudicial attitudes were also cited as a reality not only in the lives of newcomers but also for all women of color. Service providers highlighted that racial discrimination should be taken into consideration in any assessment of women of color who are living with woman abuse. As one informant put it, "If you are brown, you are treated as stupid, even if you were born and raised here." Attitudes and inaccurate assumptions by professionals were noted as problematic.

The study data indicate that involvement with child welfare creates enormous fears for women who do not have landed immigrant (i.e., legal resident) status because any involvement with authorities can be viewed negatively in the status review process. Women with precarious immigration status may fear deportation if their sponsor is the abusive partner and he is charged and convicted. They are generally apprehensive regarding involvement with authorities such as police or child welfare for fear that this will negatively impact on their application bid. For example, a police informant described feeling in a bind but confessed he would ultimately make a decision to report to immigration authorities:

If we have information in our possession about the victim or the husband we have to notify immigration. It is not uncommon where a victim is being investigated for being in the country or the husband as well. We have no choice in the matter; we have to notify immigration and whatever happens after that we have no control over.

For many newcomers to Canada, there is little understanding of the child welfare system because similar systems may not exist in their countries of origin. One VAW worker explained:

There is no question that is one of the major stumbling blocks that we find here in this area is the language and the lack of knowledge of how things do work in Canada versus where they came from or what the expectations are.

Immigrant and refugee women are often confronted with language and cultural barriers in accessing support and services after disclosing abuse. Canadian practices are foreign to many newcomers. For example, one worker from an ethno-specific service explained that some women simply do not know "how to separate from their husbands" noting that in some parts of China both spouses must agree and sign for a separation to occur, so they assume it is the same in Canada.

For women with physical disabilities, many issues arise around the decision to leave an abusive relationship. Often these women either rely on their partner for physical support or have established a network of care that would be difficult to recreate if they left their current surroundings. As one VAW service provider described:

Another barrier is physical accessibility or inaccessibility, so not even being able to get into an agency. A whole other issue is if some women want to leave and their partner 
is also their caregiver, where do they go? And women with disabilities who have children it is the whole fear of them not being viewed as competent parents.

\section{Discussion}

The occurrence of DV signals a crisis in the family. Whether disclosure occurs by the victim or through outside party detection/intervention, parents and children are in need of sensitive and effective responses in the immediate crisis. The manner in which systems respond to this crisis is critical to the trajectory the family will follow and may have an impact on outcomes. The urgency and necessity of assessing the consequences of child welfare policies in the lives of women and children is clearly demonstrated in this study because these policies drive the actions of helping professionals. Legislative amendments to the Ontario Child and Family Services Act were developed with the "best interests of the child" at heart, based on the best available child research. In the 1990s, DV was not being identified by child welfare workers. Once awareness was heightened through the convergence of DV and child welfare research, exploratory probing revealed a high incidence in families investigated by child protection workers. As well, public awareness was increasing about the problem of children exposed to DV that resulted in more reporting. These study data strongly suggest that although the legislation was well intentioned, both negative and positive outcomes have emerged.

Although the intent of the legislation was informed by current research and supported by various helping professionals serving children, numerous concerns have also emerged. Reluctance of women to disclose DV or seek services for their families; isolation between helping professionals from different sectors; increased surveillance of mothers; barriers due to race, class, sexual orientation, ability, and immigration status; and lack of accountability of perpetrators were predominant themes and subthemes identified from the interview data. While most study participants, service providers, and clients noted that the "spirit of the Act" was well meaning, problems with its implementation and subsequent impact on families and services have been documented (penalizing mothers, inhibiting disclosure especially for marginalized women, and taxing already stressed systems are among the three most significant consequences).

Unfortunately, similar findings from previous research that clearly documents the substantial implications of child welfare policies for children exposed to DV have not been taken into account throughout the implementation process in Ontario. For example, similar legislation in Minnesota was repealed in 2000 after most counties experienced a $50 \%-100 \%$ increase in reporting of children exposed to adult DV (see Minnesota Association of Community Social Service Administrators, 2000). Of interest, this was the same year that Ontario, Canada, introduced changes to the Child and Family Services Act to strengthen exposure to "adult conflict" under "duty to report." Since Minnesota's instatement and subsequent retraction of definitional changes in their child welfare legislation, Edleson, Gassman-Pines, and Hill (2006) have deconstructed the pivotal events leading up to these changes and tracked the aftermath. They conclude that legislators made changes to language - viewing child exposure to DV as neglect-without fully understanding the resounding impact on practice. They did not anticipate the floodgate of referrals that resulted. Furthermore, sufficient funding was not infused for this influx, and therefore, these new cases were not dealt with adequately (Edleson et al., 2006). Our data indicate that a very similar scenario has unfolded 
in Ontario where one of the largest child welfare organizations reported a $500 \%$ increase in referrals between 2000 and 2003 (environmental scan, Children's Aid Society of Toronto, 2003).

In response to increasing referrals for service, valiant efforts have been made by sector professionals in this study's jurisdiction to respond in more integrated, coordinated, and culturally responsive ways. Partnerships, collaboration agreements, and protocols have been developed across several of the sectors, and cross-sectoral trainings have been initiated. In particular, one child protection agency has formed a team of specialists that offers an alternative response specifically for DV cases. Yet funding has not been increased to all child welfare services or community-based agencies to the degree needed to address the growing demand for more specialized DV and child protection services, nor has it been increased to develop greater community capacity. Despite the hard work by professionals to respond to current demands, their efforts are undermined by structural limitations.

Data from our study support findings in the literature regarding mothers feeling penalized by these policies (Edleson, 1998, 2004; Jaffe et al., 2003; Magen, 1999; Magen et al., 2000; Sev'er, 2002). In this study, there were also examples of mothers citing incidents where child welfare investigations were helpful, especially when the intervention was the catalyst for leaving an unhealthy family environment for the sake of children. However, these positive accounts were in the minority and contrasted by the high volume of narratives about reluctance to report and fears around any child welfare involvement. These fears might be generalized to other services that are perceived to have "duty to report" obligations, such as shelters, raising concerns that some women may not disclose or report partner violence, ultimately resulting in a lack of service utilization for women and children in dan- gerous situations. Based on theories indicating that disclosure is closely linked with seeking and accessing services, without self-disclosure, opportunities for counseling and support are greatly minimized (Cepeda-Benito \& Short, 1998; Kelly \& Achter, 1995; Vogel \& Wester, 2003).

\section{Implications for Practice and Research}

The warning bell was sounded on potential consequences of child welfare policies on families and services as early as 1999 (Edleson, 1998; Jaffe et al., 2003; Magen, 1999; Magen et al., 2000; Sev'er, 2002). In 2003, Jaffe et al. after reviewing and analyzing legal and policy responses to children exposed to DV went so far as to recommend, "a moratorium on legislation for children exposed to woman abuse without [such] an analysis and evaluation" (p. 212). They suggested that jurisdictions considering this type of legislation collect and analyze baseline data of the number of children exposed to woman abuse currently identified by different systems first and then evaluate the capacity of systems to respond to an increase in reporting before instituting legislative changes. These steps were not taken in Ontario, therefore necessitating reforms of the legislation in the current child welfare transformation planning, a new initiative to address these and other problems in child welfare service delivery (Ontario Child Welfare Transformation Plan). Currently, several jurisdictions across Canada are moving toward adopting differential response models, including Ontario where this model has been explored through a recent round of child welfare reforms (Ontario Child Welfare Transformation Plan, 2005). Since the completion of this study in 2005 a model of differential response has been implemented in Children's Aid Societies of Ontario and is undergoing evaluation of impact in cases of domestic violence. 
Support for differential response models across North America has been driven in part by a dramatic increase in reporting but also by feedback from mothers who fear child welfare involvement and possible apprehension of their children (Devoe \& Smith, 2003). Differential response (Waldfogel, 1998) is an approach that relies on accurately classifying cases into varying levels of risk wherein children referred to child welfare for exposure to DV would be initially screened as low or high risk and referred accordingly, with only the more serious cases going to child protection services and low-risk cases being referred to voluntary community-based services. American studies have just begun to assess the impact of the implementation of differential response in various jurisdictions (English, Edleson, \& Merrick, 2005; Kohl, Barth, Hazen, \& Landsverk, 2005). Preliminary findings indicate that in jurisdictions operating with a differential response model, the majority of cases of DV are less likely to be subjected to full investigative procedures from child welfare authorities. A smaller number of cases where DV is identified as a risk factor are put through full investigations; cases that are subjected to full investigations are usually those with co-occurring forms of maltreatment. In these cases, there is a higher likelihood of ongoing child welfare involvement and apprehension. As well, there is a high number of DV indicated cases that are rereferred to the child welfare system and it is unclear as to why (English et al., 2005; Jaffe et al., 2003). Evaluative studies of this nature are scant. More research is critically needed.

Additionally, Edleson (2004) points out that the research on the impact of exposure to DV for children is not adequately integrated into practice responses. Policy and practice should reflect that not all children are affected in the same ways and to the same degree and that developmental factors and family characteristics should be taken into account.
Finally, the problem of dealing with the perpetrator of violence has been a thorny issue - one that has been identified throughout the literature (Strega, 2006) and clearly emerged in our data. Perpetrators of violence are often avoided in child welfare systems for lack of training, mandate, or accessibility. Alaska has lead the way in carving out new legislation that moves to exclude the perpetrator of the violence from the family rather than putting the burden on the victims to flee with their children (Edleson et al., 2006). While this issue was raised in consultations to legislative reforms in Ontario, it remains unresolved.

The current investigation was limited to a small, nonrepresentative sample of child welfare involving families, child welfare workers, administrators, and other professionals who relayed their experiences with the child welfare system when working with DV cases. It would be interesting to see if these findings play out on a larger level. In other words, are these trends true for a larger, representative sample of families? Future research should focus on establishing the effectiveness of differential response models in child welfare before these are implemented. One significant area for investigation is whether safety and risk assessment tools used in child welfare are valid in cases involving DV. Another is whether adequate and effective community resources are available for referral and ongoing service. As well, given the lack of rigorous longitudinal studies detailing services provision in child welfare, there are questions about whether cases in the differential deemed to be "low risk" or "no risk" receive appropriate, adequate, and effective services.

Our findings offer unique insights into how the legislation has impacted abused mothers and service providers. More consideration needs to be given to how the changes in legislation have impacted on disclosure of DV; on the help-seeking behaviors of abused women; 
and on those who provide child welfare and VAW services. Our findings were consistent with previous research, and we echo the recommendations made by experts in the field who have gone before us. Although in Ontario we are moving forward with this legislation, we feel strongly that differential response models should be primarily introduced as pilot studies, rigorously evaluated, and only implemented when there are assurances that appropriate, adequate, and effective services are available to meet the complex needs of the communities they are designed to serve.

\section{Funding}

United Way of Greater Toronto; Social Sciences and Humanities Research Council of Canada.

\section{Acknowledgments}

The authors wish to thank the participants in this study for sharing their time and experiences. We also extend our appreciation to Child Development Institute of Toronto for their support and involvement in the study. Conflict of Interest: None declared.

\section{References}

Alaggia, R. (2001). Cultural and religious influences in maternal response to intrafamilial child sexual abuse: Charting new territory for research and treatment. Journal of Child Sexual Abuse, 2, 41-60.

Alaggia, R., \& Maiter, S. (2006). Domestic violence and child abuse: Issues for immigrant and refugee families. In R. Alaggia \& C. Vine (Eds.), Cruel but not unusual: Violence in Canadian families. (pp. 99126). Waterloo: Wilfrid Laurier University Press.

Alaggia, R., \& Trocmé, N. (2004). Roundtable on child welfare practices in domestic violence cases.

Toronto: University of Toronto.

Cepeda-Benito, A., \& Short, P. (1998). Selfconcealment, avoidance of psychological services and perceived likelihood of seeking professional help. Journal of Counseling Psychology, 45, 58-64. Children's Aid Society of Toronto (2003). Long range plan 2003: Beyond environmental scan. Toronto, Ontario, Canada : Children's Aid Society of Toronto. Child Welfare Transformation (2005): A strategic plan for a flexible, sustainable and outcome oriented service delivery model, Ministry of Children and Youth Services, Ontario, Canada, June 2005.

Cummings, E. M. (1998). Children exposed to marital conflict and violence: Conceptual and theoretical directions. In G. W. Holden, R. A. Geffner, \& E. N. Jouriles (Eds.), Children exposed to marital violence: Theory, research, and applied issues. Washington, DC: American Psychological Association. p. 55-93.

Davis, L. V., \& Srinivason, M. (1995). Listening to the voices of battered women: what helps them escape violence. Affilia, 10, 49-69. Thousand Oaks, CA: Sage.

Devoe, E. R., \& Smith, E. L. (2003). Don't take my kids: Barriers to service delivery for battered mothers and their young children. Journal of Emotional Abuse, 3, 277-294.

Edleson, J. (1998). Responsible mothers and invisible men: Child protection in the case of adult domestic violence. Journal of Interpersonal Violence, 13, 294-298.

Edleson, J. (1999). Children witnessing of adult domestic violence. Journal of Interpersonal Violence, 14, 839-870.

Edleson, J. L. (2004). Should childhood exposure to adult domestic violence be defined as child maltreatment under the law? In P. G. Jaffe, L. L. Baker, \& A. J. Cunningham (Eds.), Protecting children from domestic violence: Strategies for community intervention (pp. 8-29). New York: Guilford Press.

Edleson, J. L., Gassman-Pines, J., \& Hill, M. B. (2006). Defining child exposure to domestic violence as neglect: Minnesota's difficult experience. Social Work, 51, 167-174.

English, D. J., Edleson, J. L., \& Herrick, M. E. (2005). Domestic violence in one state's child protective case load: A study of differential case dispositions and outcomes. Children and Youth Services Review, 27, 1183-1201. 
Fallon, B., Trocmé, N., MacLaurin, B., Knoke, D., Black, T., Daciuk, J., et al. (2005). Ontario incidence study of reported child abuse and neglect, OIS-2003: Major findings. Toronto, Ontario, Canada: Centre of Excellence for Child Welfare.

Gondolf, E., Yllo, K., \& Campbell, J. (1997). Collaboration between researchers and advocates. In G. K. Kantor \& J. Jasinski (Eds.), Out of darkness: Contemporary research perspectives on family violence (pp. 255-267). Thousand Oaks, CA: Sage.

Hilton, Z. N. (1992). Battered women's concerns about their children witnessing wife assault. Journal of Interpersonal Violence, 7, 77-86.

Jaffe, P. G., Crooks, C. V., \& Wolfe, D. A. (2003). Legal and policy responses to children exposed to domestic violence: The need to evaluate intended and unintended consequences. Clinical Child and Family Psychology Review, 6, 205-213.

Kelly, A.E. \& Achter, J.A. (1995). Self concealment and attitudes toward counseling in university students. Journal of Counseling Psychology, 42, 40-46.

Kohl, P. L., Barth, R. P., Hazen, A. L., \& Landsverk, J.A. (2005). Child welfare as a gateway to domestic violence services. Children and Youth Services Review, 27, 1203-1221.

Lee, M.-Y. (2000). Understanding Chinese battered women in North America: A review of the literature and practice implications. In D. de Anda \& R. M. Becerra (Eds.), Violence: Diverse populations and communities (pp. 215-241). New York: Haworth Press.

Magen, R. H. (1999). In the best interests of battered women: Reconceptualizing allegations of failure to protect. Child Maltreatment, 4, 127-135.

Magen, R., Conroy, K., \& Del Tufo, A. (2000). Domestic violence in child welfare preventative services: Results from an intake screening questionnaire. Children \& youth services review. Special issue: Woman abuse and child protection: $A$ tumultuous marriage (Part I), 22, 251-274.

Maguire, P. (1997). Doing Participatory Action Research: A Feminist Approach. Amherst: University of Massachusetts Press.

Mahoney, M. (1991), Legal images of battered women: Redefining the issue of separation. Michigan Law Review, 90, 1-94.
McDonald, S. (1999). Not in the numbers: Immigrant women and domestic abuse. Canadian Woman Studies, 19, 163-167.

McGee, C. (2000). Childhood experiences of domestic violence. Philadelphia, PA: Jessica Kingsley.

Minnesota Association of County Social Service Administrators Children's Committee (2000). Co-occurring spouse abuse and child abuse: Domestic violence fiscal note — January 2000. St. Paul, MN: Author.

Nicholson v. Williams. (2002). 203 F. Supp. 2d 153, E.D. N.Y.

Pagelow, M. (1992). Adult victims of domestic violence. Journal of Interpersonal Violence, 7, 187-120.

Pratt, A. (1995). New immigrant and refugee battered women: The intersection of immigration and criminal justice policy. In M. Valverde, L. MacLeod, \& H. Johnson (Eds.), Wife assault and the criminal justice system: Issues and policies (pp. 84-104). Toronto, Ontario, Canada: Centre for Criminology, University of Toronto.

Renzetti, C. M. (1997). Violence and abuse among same-sex couples. In A. P. Cardarelli (Ed.), Violence between intimate partners: Patterns, causes and effects. Toronto, Ontario, Canada: Allyn and Bacon.

Riger, S. (1999). Working together: Challenges in collaborative research on violence against women. Violence Against Women, 5, 1099-1117.

Sev'er, A. (2002). A feminist analysis of flight of abused women, plight of Canadian shelters: Another road to homelessness. Journal of Social Distress and Homelessness, 11, 307-324.

Shaffer, M. \& Bala, N. (2004). The role of family courts in domestic violence: The Canadian experience, 171-187. In Jaffe, P., Baker, L. \& Cunningham, A. (Eds). Protecting Children from Domestic Violence: Strategies for Community Intervention. New York: The Guilford Press.

Shirwadkar, S. (2004). Canadian domestic violence policy and Indian immigrant women. Violence Against Women, 10, 860-879.

Statistics Canada (Canadian Centre for Justice Statistics). (2005). Family violence in Canada: A statistical profile 2005. Ottawa, July 2005 
(No. 85-2324-XIE). Ottawa, Canada: Minister of Industry.

Strega, S. (2006). Failure to protect? Child welfare interventions when men beat mothers. In R.

Alaggia \& C. Vine (Eds.), Cruel but not unusual: Violence in Canadian families. Waterloo: Wilfrid Laurier University Press.

Taylor-Butts, A. (2005). Shelters for abused women. Juristat (Catalogue no. 85-002, Vol. 25, No. 3).

Ottawa, Canada: Canadian Centre for Justice Statistics.

Trocmé, N., Fallon, B., MacLaurin, B., Daciuk, J., Felstiner, C., Black, T., et al. (2005). Canadian incidence study of reported child abuse and neglect-
2003: Major findings. Ottawa: Minister of Public Works and Government Services Canada.

Vogel, D.L. \& Wester, S.R. (2003). To seek help or not to seek help: The risks of self-disclosure. Journal of Counseling Psychology, 50(3), 351-361.

Waldfogel, J. (1998). Rethinking the paradigm for child protection. Future of Children, 8, 104-119.

Wolfe, D. A., Crooks, C., Lee, V., McIntyre-Smith, A., \& Jaffe P. (2003). The effects of exposure to domestic violence: A meta-analysis and critique. Clinical Child and Family Psychology Review, 6, 171-187. 